\title{
Haemochromatosis gene mutations and risk of coronary artery disease
}

\author{
Eva Battiloro ${ }^{1}$, Domenico Ombres ${ }^{2}$, Ester Pascale ${ }^{3}$, Ettore D'Ambrosio ${ }^{4}$, Roberto Verna ${ }^{1}$ \\ and Marcello Arca
}

${ }^{1}$ Cattedra di Patologia Clinica, Dipartimento di M edicina Sperimentale e Patologia; ${ }^{2}$ Istituto di Terapia Medica Sistematica, Università di Roma 'La Sapienza', Rome; ${ }^{3}$ Dipartimento di Medicina Sperimentale, Università de L'Aquila, L'Aquila; ${ }^{4}$ Istituto di Medicina Sperimentale, CNR, Rome, Italy

The identification of mutations in the haemochromatosis gene (HFE) (C282Y and H63D) provides the unique opportunity to test whether genetic variants that are associated with tissue iron accumulation may influence the risk of coronary atherosclerosis. To this aim the prevalence of C282Y and H63D mutations was determined in 174 patients with angiographically documented CAD ( $>50 \%$ stenosis) and history of MI, 187 healthy free-living individuals and 142 blood donors. C282Y and H63D mutations were not found to be more frequent in coronary patients as compared to controls. Moreover, these HFE variants were unrelated to the severity of coronary atherosclerosis. These findings did not provide evidence of an association between HFE mutations and the presence of coronary atherosclerosis or its major ischaemic complications, thus indicating that HFE mutations are poor genetic markers of coronary risk. European Journal of Human Genetics (2000) 8, 389-392.

\section{Keywords: iron; haemochromatosis; coronary artery disease; linkage; mutations}

\section{Introduction}

The observation that iron increases free radical production and oxidative stress leads to the hypothesis that iron accumulation might contribute to in vivo LDL peroxidation and, thereby, to atherosclerosis. ${ }^{1,2}$ However, the relationship between iron status and atherosclerotic disease remains controversial. ${ }^{3-8}$

Body iron metabolism is, at least in part, genetically influenced, and the recent identification of the gene for hereditary haemochromatosis $(\mathrm{HH})$ on chromosome 6 has significantly improved our understanding of the molecular basis of iron metabolism. ${ }^{9} \mathrm{HH}$ is an autosomal recessive disease that leads to progressive tissue iron accumulation and multiorgan dysfunction. ${ }^{10}$ Two mutations have been detected in the HFE gene which are related to $\mathrm{HH}: \mathrm{C} 282 \mathrm{Y}$ and H63D. ${ }^{11}$ The C282Y mutation was also found in a large majority of patients with sporadic porphyria cutanea tarda, ${ }^{12}$

Correspondence: Marcello Arca, MD, Istituto di Terapia Medica Sistematica, Università di Roma 'La Sapienza', Policlinico Umberto I, Viale del Policlinico 155, 00161 Roma, Italy. Fax: +39 06-4440290; E-mail: itmsricci@caspur.it

Received 28 July 1999; revised 24 December 1999; accepted 7 January 2000 another condition associated with severe hepatic siderosis; thus it is considered a disease-causing mutation. The role of $\mathrm{H} 63 \mathrm{D}$ is less defined and it seems to cause $\mathrm{HH}$ only when inherited together with the $\mathrm{C} 282 \mathrm{Y}$ mutation. ${ }^{13}$ However, Garry et $\mathrm{al}^{14}$ reported that healthy carriers of either mutation show increased levels of stored iron. This observation together with the relatively high frequency of HFE alleles in the general population ${ }^{13}$ raised the possibility that heterozygosity for HFE mutations may significantly impact on the risk of atherosclerosis.

The present investigation was designed with the objective to assess whether mutations in the HFE gene might be associated with increased risk of coronary artery disease (CAD).

\section{Methods \\ Subjects}

A total of 503 Italian subjects was included in the study. Case patients consisted of 174 consecutive patients, $>40$ years old, with positive coronary angiograms (at least one vessel with $>50 \%$ sten osis) and a history of MI. Diagnosis of previous MI was verified by typical ECG changes and elevation of serum 
enzymes (CPK, AST and LDH). Patients with thyroid, liver or renal diseases were excluded. At the time of blood sampling, patients were under their usual cardiovascular medications. Two independent groups of subjects were evaluated as controls. The first group (population controls) included $>40$-year-old, unrelated individuals randomly extracted from a population of 998 subjects participating in a community-based control programme of coronary risk factors. No preselection criteria were used. After selection, those $(n=187$ ) with no evidence of CAD (no history of angina and normal resting $\mathrm{ECG}^{15}$ ) were considered for genetic analysis. The second group consisted of 145 individuals, 47 men and 98 women, (mean age 40 years) selected from a blood donor bank. No information on CAD status was available for blood donors. A structured questionnaire was used to characterise both case patients and population controls, as previously reported. ${ }^{16}$ Clinical and biochemical characteristics of case patients and population controls are shown in Table1. With the exception of hypercolesterolaemia, population controls were characterised by a lower prevalence of major risk factors. Among population controls, 20 subjects (11\%) were taking antihypertensive drugs and 25 subjects (13\%) were taking lipid-lowering medications.

Fasting blood samples for routine laboratory examinations, lipid measurements and DNA isolation were obtained early in the morning after an overnight fast. Plasma total cholesterol and triglyceride, and HDL-cholesterol concentrations were measured as reported. ${ }^{16} \mathrm{LDL}$ cholesterol levels were calculated by the Friedewald formula.

\section{Determination of HFE mutations}

Detection of HFE mutations were performed by combination of PCR with an allele-specific oligonucleotide (ASO) technique. ${ }^{17}$ PCR was performed using the following pairs of primers: 5'-TGGCAAGGGTAAACAGATCC-3' and 5'-CTCAGGCACTCCTCTCAACC-3' (for C282Y) and 5'-ACATGGTTAAGGCCTGTTGC-3' and 5'-GCCA-

Table 1 Prevalence of selected risk factors in case patients and population controls

\begin{tabular}{|c|c|c|c|}
\hline Variable & $\begin{array}{l}\text { Case } \\
\text { patients } \\
(n=175)\end{array}$ & $\begin{array}{l}\text { Population } \\
\text { controls } \\
(n=187)\end{array}$ & $\mathrm{P}$ \\
\hline Age (years) & $59.5 \pm 9.5$ & $59.8 \pm 11.6$ & n.s. \\
\hline $\mathrm{M} / \mathrm{F}$ & $141 / 34$ & $90 / 97$ & $<0.0001$ \\
\hline $\mathrm{BMI}\left(\mathrm{kg} / \mathrm{m}^{2}\right)$ & $26.7 \pm 4.2$ & $26.5 \pm 3.5$ & n.s. \\
\hline Menopause $(\%)^{a}$ & $32(94.1)$ & $76(78.0)$ & n.s. \\
\hline Current smokers (\%) & 89 (51.0) & $24(13.1)$ & $\varangle 0.0001$ \\
\hline History of hypertension (\%) & $90(51.4)$ & $55(30.0)$ & $\lessdot 0.0001$ \\
\hline History of diabetes mellitus (\%) & $27(15.4)$ & $3(1.6)$ & $\varangle 0.0001$ \\
\hline Hypercholesterolaemia $(\%)^{\mathrm{b}}$ & $47(26.8)$ & $78(42.4)$ & $\lessdot 0.002$ \\
\hline Hypertriglyceridaemia $(\%)^{b}$ & $52(29.7)$ & $40(21.7)$ & n.s. \\
\hline
\end{tabular}

Data are reported as numbers (percentage in parentheses) and means \pm SD; BMI: Body Mass Index; M: male; F: female; apercentage has been calculated over female sample; ${ }^{b} \mathrm{Hypercholesterolaemia} \mathrm{was}$ defined as LDL cholesterol $>160$ mg/dl; hypertriglyceridaemia as total triglycerides $\geq 200 \mathrm{mg} / \mathrm{dl}$.
CATCTGGCTTGGAAATT-3' (for H63D) and carried out in 30 cycles consisting of $30 \mathrm{~s}$ at $94^{\circ} \mathrm{C}, 1 \mathrm{~min}$ at $60^{\circ} \mathrm{C}\left(55^{\circ} \mathrm{C}\right.$ for the $\mathrm{H} 63 \mathrm{D}$ mutation), $30 \mathrm{~s}$ at $72^{\circ} \mathrm{C}$. Digoxigenin-labelled oligonucleotides for the detection of the $\mathrm{C} 282 \mathrm{Y}$ mutation were: 5'-TATACGTGCCAGGT-3' (wild-type) and 5'-TATACGTACCAGG-3' (mutant); those for the H63D detection were: 5'-CTATGATCATGAGAG-3' (wild-type) and 5'-CTATGATGATGAGAG-3' (mutant). The typical results for $C 282 Y$ detection are reported in Figure1. Twenty samples were genotyped using both the ASO and the restriction enzyme technique; ${ }^{11}$ concordance was $100 \%$.

\section{Statistical analysis}

Categorical variables were compared by $\chi^{2}$ or Fisher's exact tests and continuous variables by Student's t test. The frequencies of HFE alleles and genotypes were obtained by direct count and the departure from the Hardy-Weinberg equilibrium was evaluated by $\chi^{2}$ test. Genotype distributions were compared by $2 \times 2$ and $2 \times 3$ contingency tables and $\chi^{2}$ analysis. The relations between mutations in the HFE gene and clinical and biochemical variables were evaluated by ANOVA. All computations were carried out with a StatView Statistical package for Macintosh.

\section{Results}

The prevalence of HFE mutation s in case patients, population controls and blood donors is shown in Table2. In all groups, the frequencies of HFE genotypes were in Hardy-Weinberg equilibrium and did not show any difference according to age and sex. No homozygote for the C282Y mutation was found. Four CAD patients (2.3\%) were heterozygous for the $\mathrm{C} 282 \mathrm{Y}$, but this frequency was not significantly different $(P<0.3)$ from that observed in both population controls (1.6\%) and blood donors (4.3\%). Both homozygous and

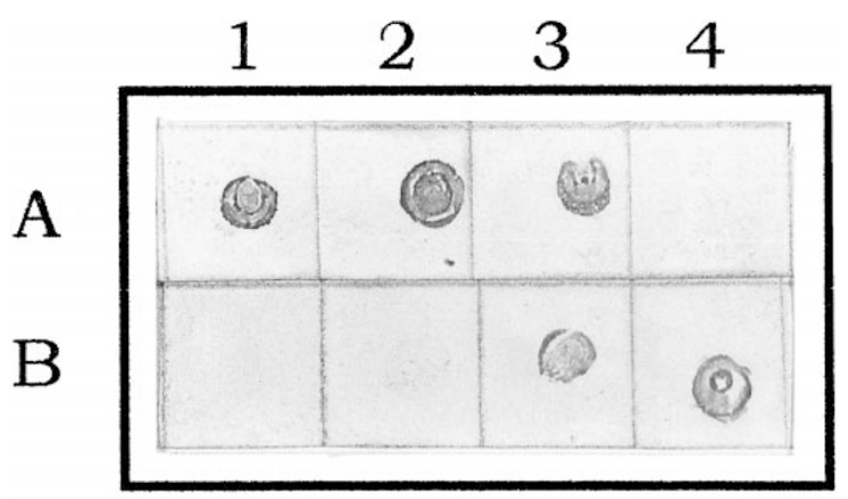

Figure 1 Detection of C282Y mutation in the HFE by ASO techniques. Membranes were hybridised either with wild-type (Panel A) or with mutant digoxigenin-conjugated oligonucleotides probes (Panel B). Lanes 1 and 2: homozygous wild-type carriers; lane 3: heterozygous carrier; lane 4: homozygous mutant carriers; this patient was affected by clinical haemochromatosis. 
Table 2 Genotype and allele frequencies for C282Y and H63D mutations in case patients and control groups

\begin{tabular}{lccc}
\hline & $\begin{array}{l}\text { Case } \\
\text { patients } \\
(\mathrm{n}=175)\end{array}$ & $\begin{array}{l}\text { Population } \\
\text { controls } \\
(\mathrm{n}=187)\end{array}$ & $\begin{array}{l}\text { Blood } \\
\text { donors } \\
(\mathrm{n}=145)\end{array}$ \\
\hline Genotype: & No. of subjects/total & number $(\%)$ \\
CC & $170 / 174(97.7)$ & $184 / 187(98.4)$ & $133 / 142(95.7)$ \\
CY & $4 / 174(2.3)$ & $3 / 187(1.6)$ & $6 / 142(4.3)$ \\
YY & 0 & 0 & 0 \\
HH & $121 / 174(69.5)$ & $131 / 187(70.0)$ & $104 / 142(73.2)$ \\
HD & $45 / 174(25.9)$ & $51 / 187(27.3)$ & $37 / 142(26.0)$ \\
DD & $8 / 174(4.6)$ & $5 / 187(2.7)$ & $17 / 142(0.8)$ \\
Mutant allele: $(\%)$ & & \\
Y & 1.2 & 0.8 & 2.1 \\
D & 17.5 & 16.3 & 13.7 \\
\hline
\end{tabular}

Detection of C282Y mutation was missing for one case patient and three blood donors. $\chi^{2}=2.41, \mathrm{P} \varangle 0.3$ for comparison of $\mathrm{C} 282 \mathrm{Y}$ and $\chi^{2}=4.52, P<0.4$ for comparison of H63D genotypes between case patients and control groups.

heterozygous carriers for H63D mutations were detected. Although homozygosity for the H63D mutation tended to be higher in patients as compared with the control groups, the frequencies of the mutated $D$ allele did not differ between the groups $(P<0.4)$. Two subjects were compound heterozygotes for both HFE mutations, but were detected among population controls $(1.1 \%)$. Similar results were obtained when comparisons were made in men and women separately (data not shown).

With regard to CAD severity, patients without significantly diseased vessels showed similar frequency of HFE mutated alleles $(0.8 \%$ for $Y$ and $17.1 \%$ for $D$ allele (compared with patients with one or two diseased vessels $(1.5 \%$ for $Y$ and $14.8 \%$ for $D$ allele) or those up to three diseased vessels $(0.7 \%$ for $Y$ and $17.6 \%$ for $D$ allele).

No significant difference was found in lipid levels or other classical risk factors with respect to the HFE genotype (data not shown).

\section{Discussion}

In our study, we found no indication that the $\mathrm{C} 282 \mathrm{Y}$ and H63D mutations in the HFE gene are associated with increased risk of coronary atherosclerosis and MI.

When interpreting these results possible sources of bias must be considered. First, the study was case-controlled in design, and the subjects were not recruited prospectively. Therefore a survival bias cannot be excluded. However, assuming early mortality from CAD in individuals carrying HFE mutations, the latter would be over-represented in the control group. But it was not the case. We evaluated two independent groups of CAD-free controls, one of which was population-based. Even though angiography was not performed in population controls for ethical reasons, the use of the Rose questionnaire and ECGs to classify CAD patients in population-based screenings has been well established. ${ }^{18}$ In addition, it must be noted that the pooled prevalence of HFE mutations in controls was comparable with that previously reported in Italian healthy subjects using the restriction enzyme technique. ${ }^{19}$

The lack of association between HFE mutations and CAD may indicate that these genetic variants are not related to increased atherosclerosis. Similar conclusions were reached by Franco et $\mathrm{al}^{20}$ who did not detect any excess frequency of HFE mutations in a group of younger patients ( $<50$ years old) with premature coronary and peripheral atherosclerosis. Moreover, several epidemiological studies did not demonstrate any association between iron status and cardiovascular disease. $^{2}$ However, additional explanation must be considered. Recent studies have showed that only $64 \%$ of subjects with $\mathrm{HH}$ in Italy are homozygous for the C282Y mutation $^{19,21}$ and Pietrangelo et al $^{22}$ have just reported in an Italian family that $\mathrm{HH}$ can occur in adults who do not have these mutations in the HFE gene. Therefore, it is possible that mutations in genes other than in the HFE can contribute to the iron status and accordingly to the CAD risk in the Italian population.

In conclusion, our study did not provide evidence of a significant association between HFE mutations and the development of coronary atherosclerosis or its major ischemic complications, thus indicating that HFE mutations are poor genetic markers of risk in the general population of patients.

\section{Acknowledgements}

This study was supported in part by grant nos 95.00924.PF41 and 96.05269.ST74 (Progetto Strategico Infarto Miocardico) from the Italian National Research Council (CNR). We wish to thank Dr Antonio Candeloro for his assistance in collecting clinical data and Loredana Porcu for DNA preparation. We are also particularly grateful to Dr Gaetano Pannitteri and the cardiologists in the Cardiosurgery Department for allowing us to study their patients.

\section{References}

1 Berliner JA, Haberland ME: Role of oxidized low density lipoprotein in atherogenesis. Curr Opin Lipidol 1991; 4: 373- 381.

2 Corti MC, Gaziano M, Hennekens CH: Iron status and risk of cardiovascular disease. Ann Epidemiol 1997; 7: 62-68.

3 Lauffler RB: Iron stores and the international variation in mortality from coronary artery disease. Medical Hypotheses 1991; 35: 96-102.

4 Salonen JT, Hyyssonen K, Korpela H, Tuomilehto J, Seppanen R, Salonen R: High stored iron levels are associated with excessive risk of myocardial infarction in eastern Finnish men. Circulation 1992; 86: 803-811.

5 Burt MJ, Halliday JW, Powell LW: Iron and coronary heart disease. Br Med J 1993; 307: 575-576.

6 Morrison HI, Semenciw RM, Mao Y, Wigle DT: Serum iron and risk of fatal acute myocardial infarction. Epidemiology 1994; 5: 243-246.

7 Kiechl S, Aichner F, Gerstenbrand E et al: Body iron stores and presence of carotid atherosclerosis. Arterioscler Thromb 1994; 14: 1625-1630. 
8 Kiechl S, Willeit J, Egger G, Poewe W, Oberhollenzer F: Body iron stores and the risk of carotid atherosclerosis: prospective results from the Bruneck Study. Circulation 1997; 96: 3300-3307.

9 Feder JN, Gnirke A, Thomas W et al: A novel MHC classI-like gene is mutated in patients with hereditary hemachromatosis. Nat Genet 1996; 13: 399-408.

10 Witte DL, Crosby WH, Edwards CO, Fairbanks VF, Mitros FA: Practice parameter of hereditary hemachromatosis. Clin Chim Acta 1996; 245: 139-200.

11 Beutler E, Gelbert T, West $C$ et al: Mutation analysis in hereditary hemochromatosis. Blood Cell Mol Dis 1996; 22: 187-194.

12 Roberts AG, Whatley SD, Morgan RR, Worwood M, Elder GH: Increased frequency of the hemochromatosis Cys282Tyr mutation in sporadic porphyria cutanea tarda. Lancet 1997; 349: 321-323.

13 Beutler E: Genetic irony beyond hemochromatosis. Clinical effects of HLA-H mutations. Lancet 1997; 349: 296-297.

14 Garry PJ, M ontoya GD, Baumgartner RN, Liang HC, Williams TM, Brodie SG: Impact of HLA-H mutations on iron stores in healthy elderly men and women. Blood Cell Mol Dis 1997; 23: 277-287.

15 Rose GA, Blackburn H: Cardiovascular Survey Methods. WHO: Geneva, 1968 No.56.
16 Ombres D, Pannitteri G, Montali A et al: The Gln-Arg192 polymorphism of human paraoxonase gene is not associated with coronary artery disease in Italian patients. Arterioscler Thromb Vasc Biol 1998; 18: 1611-1616.

17 Saiki RK, Chang CA, Levenson $\mathrm{CH}$ et al: Diagnosis of sickle cell anemia and $\beta$-thalassemia with enzimatically amplified DNA and nonradioactive allele-specific oligonucleotide probes. N Engl J M ed 1988; 319: 537-541.

18 Rose GA, Hamilton PJS; Keen H, Reed DD, McCarteney P, Jarrett $\mathrm{RJ}$ : Myocardial ischemia, risk factors and death from coronary heart disease. Lancet 1977; 1: 105-109.

19 Carella M, D'Ambrosio L, Totaro A et al: Mutation analysis of the HLA-H gene in Italian hemochromatosis patients. Am J Hum Genet 1997; 60: 828-832.

20 Franco RF, Zago MA, Trip MD et al: Prevalence of hereditary hemochromatosis in premature atherosclerotic vascular disease. $\mathrm{Br} J$ Haematol 1998; 102: 1172-1175.

21 Piperno A, Sampietro M, Pietrangelo A et al: Heterogeneity of hemochromatosis in Italy. Gastroenterology 1998; 114: 996-1002.

22 Pietrangelo A, Montosi G, Totaro A et al: Hereditary hemocromatoissi in adults without pathogenetic mutations in the hemochromatosis gene. N Engl J Med 1999; 341: 725-732. 